\title{
Excitatory and inhibitory conditioning following uncorrelated presentations of CS and UCS
}

\author{
A. G. BAKER and N. J. MacKINTOSH \\ University of Sussex, Brighton, Sussex BN1 9QT, England
}

\begin{abstract}
In two experiments on conditioned licking in rats, we examined the effects of preexposure to a tone alone or to uncorrelated presentations of the tone and water on subsequent conditioning. Both treatments retarded excitatory conditioning in Experiment 1 and inhibitory conditioning in Experiment 2. In both cases, the uncorrelated procedure caused more severe retardation.
\end{abstract}

Nonreinforced presentations of a stimulus usually retard subsequent conditioning when that stimulus serves as a conditioned stimulus (CS) signaling reinforcement. The effect was termed latent inhibition by Lubow and Moore (1959), but this may be misleading, for there is now considerable evidence that such treatment does not turn the stimulus into a Pavlovian inhibitor. Reiss and Wagner (1972) used a summation test of inhibition in a study of eyelid conditioning in rabbits, and found that nonreinforced presentations of a tone or vibratory stimulus reduced, rather than increased, the extent to which presentation of that stimulus in conjunction with a previously reinforced light disrupted responding to that light. Rescorla (1971), in a study of conditioned suppression in rats, and Halgren (1974), in a study of instrumental discrimination learning in rats, reported that nonreinforced preexposure to a particular stimulus retarded subsequent learning not only when that stimulus signaled reinforcement, but also when it signaled the absence of reinforcement. In Rescorla's experiment, rats were preexposed to a tone, and were subsequently conditioned to a light signaling shock. Interspersed with reinforced trials to the light were nonreinforced trials to a tone-light compound. Preexposure to the tone did not affect performance on reinforced light trials, but did retard the development of inhibitory conditioning on tone-light trials.

Presentation of a stimulus in the absence of all reinforcement is neither the only nor the most effective way of retarding conditioning to that stimulus. Uncorrelated presentations of a particular stimulus and reinforcer, although sometimes resulting in significant excitatory conditioning to that stimulus (e.g., Kremer, 1971), especially when the schedule

This research was supported by a grant from the United Kingdom Science Research Council. Requests for reprints should be sent to A. G. Baker, who is now at the Department of Psychology, McGill University, Stewart Biological Sciences Building, 1205 McGregor Avenue, Montreal, Quebec, Canada H3A 1 B1. allows several pairings of the two events early in training (Benedict \& Ayres, 1972), has also been shown to produce a more lasting impairment of subsequent conditioning than that produced by exposure to the stimulus alone (Gamzu \& Williams, 1971; Kremer, 1971; Mackintosh, 1973). We have also observed, in an unpublished experiment, that an uncorrelated treatment, although retarding excitatory conditioning, does not turn a stimulus into a conditioned inhibitor as measured by a summation test (see also Rescorla, 1966; Weisman \& Litner, 1969). The purpose of the present experiments was to see if, as Rescorla (1971) and Halgren (1974) showed for latent inhibition, uncorrelated presentations of a stimulus and reinforcer would retard both excitatory (Experiment 1) and inhibitory (Experiment 2) conditioning to that stimulus.

\section{EXPERIMENT 1}

\section{Method}

Subjects and Apparatus. The subjects were 36 male hooded rats from the colony maintained at the University of Sussex, weighing approximately $300 \mathrm{~g}$ at the beginning of the experiment. They were kept in cages of four, with continuous access to food. Beginning 10 days before training, they were gradually accustomed to a deprivation schedule which eventually permitted only 30 min access to water each day. Throughout the experiment, they received their daily ration of water immediately after their training session.

The apparatus consisted of four identical chambers, housed in sound-attenuating shells. The chambers measured $20 \times 20 \times$ $20 \mathrm{~cm}$ and had three walls made of black Perspex and one, serving as a door, of transparent Perspex. The ceiling was made of white Perspex, and the floor of stainless steel rods. A stainless steel drinking tube, insulated except at the tip, protruded $2.24 \mathrm{~cm}$ into the chamber in the center of one of the walls, $3.75 \mathrm{~cm}$ from the floor. The tube was connected to a water reservoir via a peristaltic pump, which, when operated, delivered water at a rate of $10 \mathrm{drops} / \mathrm{min}$. The rats' contacts with the tube were recorded by a contact relay.

The chamber was permanently illuminated with a very dim light provided by a $240-\mathrm{V}, 60-\mathrm{W}$ strip lamp mounted above the ceiling, switched through a solid state dimming circuit. Two stimuli were used as CS: A light, produced by turning on the overhead light 
at full intensity, and a $4,000-\mathrm{Hz}, 80-\mathrm{dB}$ (re $20 \mu \mathrm{N} / \mathrm{m}^{2}$ ) tone, produced by a Campden Instruments audio generator through a speaker mounted $8.5 \mathrm{~cm}$ above the drinking tube.

Design and Procedure. After 1 preliminary day, the experiment consisted of three stages. In Stage 1, all subjects received conditioning trials with the light serving as CS; in Stage 2, the subjects were divided into four groups, matched on the basis of their performance at the end of Stage 1, and received different experimental treatments; in Stage 3, all subjects received conditioning trials with the tone serving as CS.

On Day 1, all subjects received a single 18-min session during which there were five water reinforcements, with the pump being operated for $20 \mathrm{sec}$ for each reinforcement, and the interval between reinforcements ranging from 2 to $4 \mathrm{~min}$. All subjects licked at the water tube during this preliminary session. In Stage 1, all subjects received 10 sessions of conditioning to the light. Daily sessions were $35 \mathrm{~min}$ long, and contained 10 trials with an average interval of $3 \mathrm{~min}$ (range 2 to $4 \mathrm{~min}$ ) between trials. On each trial, the CS was turned on for $30 \mathrm{sec}$ and water was delivered during the last $20 \mathrm{sec}$ of the CS. Contacts with the drinking tube were recorded during the first $10 \mathrm{sec}$ of the $\mathrm{CS}$ and during the $10 \mathrm{sec}$ immediately preceding each CS. Conditioning to the light did not form an integral part of the design of this experiment. It was included, first, to increase the similarity between this experiment and Experiment 2, where it was a necessary feature of the design, and, secondly, to provide a basis for equating subjects in the four experimental groups in terms of their rate of conditioning.

At the end of Stage 1, the four subjects with the lowest conditioning scores were discarded and the remaining 32 subjects were divided into four groups of eight, equated for terminal level of conditioning to the light. Stage 2 was the treatment phase of the experiment; it lasted for four 35 -min daily sessions. Group Tone/ Water received uncorrelated presentations of a 30 -sec tone and 20 -sec deliveries of water; Group Tone received nonreinforced presentations of the tone alone; Group Water received presentations of water alone; and Group Control was placed in the apparatus for each session without any other event's occurring. For Group Tone/Water, there were 10 presentations of the tone and 10 of water in each session. The tones were scheduled by dividing the session into 30 -sec intervals and assigning tones at random to 10 of these intervals, with the sole restriction that there be at least one 30 -sec interval between successive tones. The water presentations were scheduled in a similar manner by dividing the sessions into 20 -sec intervals. Four programming tapes were prepared with four different sequences of events, one for each day of Stage 2. All subjects received these tapes in the same order. Over the 4 days, there were eight occasions when the presentation of the tone overlapped the delivery of water, two on each of Days 1 and 2, three on Day 3, and one on Day 4. The first such overlap was on the fifth presentation of the tone on Day 1 .

Group Tone and Group Water received 40 presentations of the tone alone and of water alone, respectively. The distribution of these events was exactly the same as that scheduled for Group Tone/Water, being programmed by the preparation of identical tapes with only the appropriate events included.

After the end of Stage 2, all subjects received 8 days of conditioning to the tone in Stage 3. The number of trials per session and intertrial intervals were exactly the same as in Stage 1.

Statistical analysis was carried out using the method described by Rodger (1967). This method uses a decision-based rather than an experiment-based error rate, and it was chosen because it keeps the power to detect a difference between groups constant in experiments with differing numbers of groups. It is more powerful than the a posteriori methods of Scheffé (1959) and NewmanKeuls (Winer, 1971), and less powerful than protected t tests or Mann-Whitney $U$ tests. The method consists of calculating an F ratio which is compared with Rodger's (1975) test statistic. If the $F$ ratio exceeds this value, then a set of orthogonal contrasts are calculated according to the method described by Scheffé (1959). These contrasts are compared against Rodger's statistic. From these decisions, the ordinal positions of the means are inferred. The contrasts are chosen so that they are either significant or as small as possible. This restriction ensures a high correlation between the inferred means and the observed means. The a posteriori contrast $F$ ratios reported are restricted to those that were significant. The maximum value of the nonsignificant contrasts was usually kept to less than .5 , which in the present case represents a protected $t$ of less than 1.22 .

The analyses of the test phase of this and the subsequent experiment were done using daily analyses of variance, rather than the more common mixed factorial design, for two main reasons. In the first place, the variance often increases over days in tests such as the present one and the smaller variances earlier in the tests often increase the probability of claiming differences, which occur later in the tests, to be reliable. In the second place, the differences between means that are to be compared by a posteriori methods are often confounded between the main effects and the interaction so that such a posteriori tests, though possible, are very cumbersome and difficult to interpret. Use of daily analyses of variance meets both of these objections because comparisons between group means on any day are straightforward and an appropriately scaled error term is available.

\section{Results}

Because pilot work had indicated considerable variability between rats in overall rate of licking, conditioning was measured by dividing each 10-sec CS or pre-CS period into 10 1-sec intervals and assigning a score of 1 to any interval in which the subject made one (or more) contacts with the drinking tube. Pre-CS scores were then subtracted from CS scores to give the final measure of conditioning. The maximum score on any trial was thus 10 contacts.

The four experimental groups were successfully matched for terminal levels of conditioning to the light. On the last day of Stage 1, their scores ranged from 5.05 to 5.80 contacts per trial, $F<1$.

The results for conditioning to the tone are shown in Figure 1. The most evident feature of the results is that Group Tone/Water conditioned less successfully than any of the other groups, but it also appears

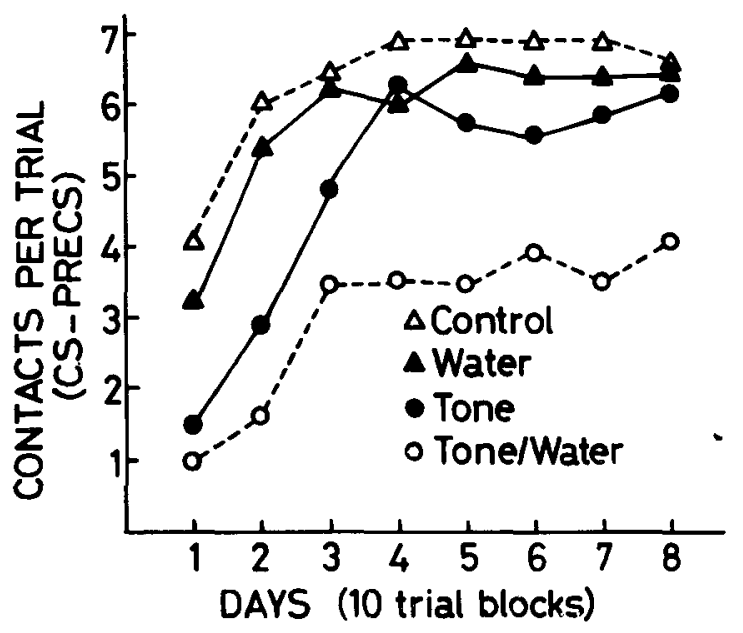

Figure 1. Mean contacts per trial during excitatory conditioning to the tone in Experiment 1. 
that Group Tone conditioned more slowly than Groups Water and Control over Days 1-3.

The results of statistical analysis of the data support this contention. The daily analyses of variance were all significant: Day $1, F(3,28)=7.08$, $\mathrm{p}<.01 ;$ Day $2, \mathrm{~F}=13.93, \mathrm{p}<.01 ;$ Day $3, \mathrm{~F}=4.54$, $\mathrm{p}<.01 ;$ Day $4, \mathrm{~F}=5.79, \mathrm{p}<.01 ;$ Day $5 ; \mathrm{F}=4.08$, $\mathrm{p}<.01$; Day $6, \mathrm{~F}=2.39, \mathrm{p}<.05 ;$ Day $7, \mathrm{~F}=3.95$, $\mathrm{p}<.01 ;$ Day $8, F=2.79, \mathrm{p}<.05$. The a posteriori contrasts indicated that on Days 1 to 3 the mean of Groups Tone/Water and Tone was less than that of Groups Water and Control: Day 1, $\mathrm{F}(3,28)=6.55, \mathrm{p}<.01 ;$ Day $2, \mathrm{~F}=12.88, \mathrm{p}<.01$; Day $3, F=3.86, p<.01$. Days $4-8$, the mean of Group Tone/Water was less than that of Groups Tone, Water, and Control: Day $4, F(3,28)=5.39$, $\mathrm{p}<.01$; Day $5, \mathrm{~F}=3.65, \mathrm{p}<.01 ;$ Day $6, \mathrm{~F}=2.31$, $\mathrm{p}<.05$; Day $7, \mathrm{~F}=3.63, \mathrm{p}<.01 ;$ Day $8, \mathrm{~F}=2.66$, $\mathrm{p}<.05$.

\section{EXPERIMENT 2}

Having confirmed, in Experiment 1, that uncorrelated presentations of tone and water would retard subsequent excitatory conditioning to the tone more than the presentation of either tone or water alone, we used the same stimuli and general procedures in Experiment 2 to examine the effects of these treatments on inhibitory conditioning to the tone.

\section{Method}

The subjects were 36 male rats from the same population as those used in Experiment 1; the apparatus was the same. Pretraining and Stages 1 and 2 were also exactly the same as in the last experiment. In particular, animals received exactly the same sequence and distributions of tones and water deliveries during Stage 2 as the equivalent groups had received in Experiment 1. The only difference in design was that Stage 3 began with one session of retraining with the light CS signaling water, and this was followed by eight sessions in which reinforced trials to the light were interspersed with nonreinforced trials to the tone-light compound. There were 10 trials per session with the usual intertrial interval, and the sequence of five light and five tone-light trials was determined by a Gellerman sequence. On both types of trial, contacts were recorded during the first $10 \mathrm{sec}$ of the CS and for the $10 \mathrm{sec}$ immediately preceding the CS.

\section{Results}

The four subjects with the lowest scores at the end of Stage 1 were discarded, and the remaining 32 rats were divided into four groups for treatment in Stage 2. The groups' scores on the last day of Stage 1 ranged from 5.5 to 6.3 contacts per trial, with no statistically significant difference between them, $F<1$.

The animals in all groups responded at a high level to the light stimulus throughout Stage 3. The groups' mean contacts per trial varied from 6.8 in Group Water to 7.4 in Group Tone, and these rates did not differ reliably, $F(3,28)=.49, \mathrm{p}>.05$. There was a significant effect of days, $F(7,196)=5.99, p<.01$; this was due to a low level of responding by all groups on Days 1 and 2 (6.4 and 6.3 contacts per trial, respectively) and to a high level of responding by all groups on Day 4 ( 7.9 contacts per trial). The Groups by Days interaction was also reliable, $F(21,196)=$ $1.91, \mathrm{p}<.01$. The only reliable daily difference found between means was on Day $5, F(3,28)=2.41$, $\mathrm{p}<.05$, when Group Tone responded at a higher rate than the control group ( 8.1 and 6.5 contacts per trial, respectively), $\mathrm{F}(3,28)=2.04, \mathrm{p}<.05$.

Figure 2, which shows the daily mean contacts to the Tone-Light compound during Stage 3, indicates that there were substantial differences in responding to this nonreinforced compound. Group Tone/ Water responded at a higher rate throughout Stage 3 than did the control group, with Group Tone and Group Water falling in between these two extremes.

The daily variance ratios indicate that the groups differed reliably on each day of this stage except Day 6: Day 1, $\mathrm{F}(3,28)=14.45, \mathrm{p}<.01 ;$ Day 2, $\mathrm{F}=3.28, \mathrm{p}<.05 ;$ Day $3, \mathrm{~F}=3.77, \mathrm{p}<.01 ;$ Day 4, F = 4.41, p <.01; Day $5, \mathrm{~F}=2.77, \mathrm{p}<.05$; Day $6, F=1.84, \mathrm{p}>.05 ;$ Day $7, F=5.10$, $\mathrm{p}<.01$; Day $8, F=3.70, \mathrm{p}<.01$. On Day 1 , a posteriori tests showed that the mean of Group Tone/Water was greater than that of Groups Tone and Water, $F(3,28)=2.44, p<.05$, while the mean of these three groups was greater than that of the control group, $F(3,28)=11.58, p<.01$. On Day 2 , the mean of Groups Tone/Water and Tone was higher than that of Groups Water and Control, $\mathrm{F}(3,28)=2.80, \mathrm{p}<.05$. On Day 3 , the mean of Groups Tone/Water, Tone, and Water was higher than that of the control group, $F(3,28)=2.82$, $p<.05$. On Day 4, the mean of Group Tone/Water was higher than that of the other groups, $F(3,28)$ $=3.63, \mathrm{p}<.01$. On Day 5 , the mean of Group

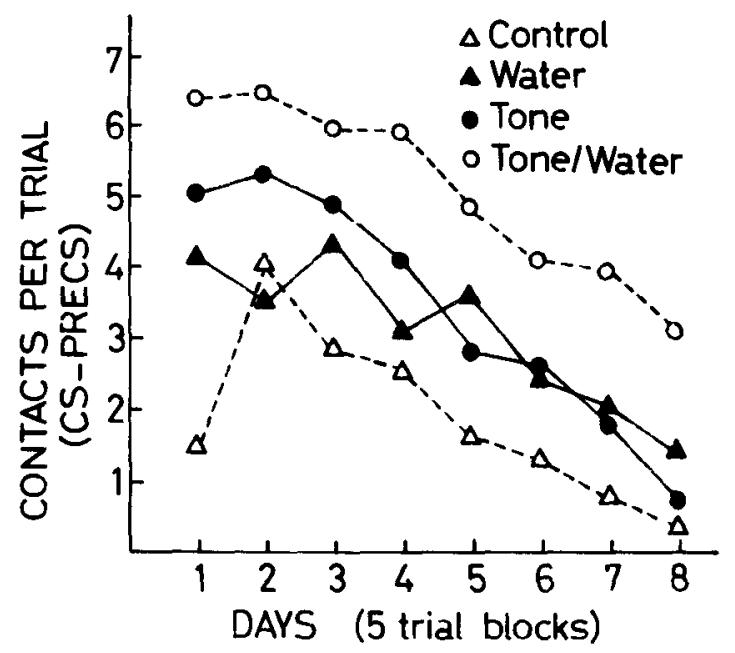

Figure 2. Mean contacts per trial to the tone-light compound during the inhibitory conditioning phase of Experiment 2. 
Tone/Water was higher than that of Groups Tone and Control, $F(3,28)=2.20, p<.05$. On Days 7 and 8 , the mean of Group Tone/Water was higher than that of the other groups: Day $7, F(3,28)=4.23$, $\mathrm{p}<.01$, and Day $8, \mathrm{~F}=3.18, \mathrm{p}<.05$.

The general implications of this set of decisions is that Group Tone/Water responded more to the tonelight compound throughout Stage 3 than the control group, with the other groups falling in between these two. There is also evidence that Group Tone did not reliably differ from Group Tone/Water until Day 4 onwards. Inspection of Figure 2 shows that these interpretations of the decisions agree well with the observed means.

\section{Discussion}

In Stage 3 of this experiment, subjects received differential conditioning with reinforced trials to the light alternating with nonreinforced trials to the tone-light compound. Differential conditioning was retarded by prior exposure to the tone alone and, more severely, by uncorrelated presentations of tone and water. We have implicitly assumed that the solution of this discrimination required the establishment of inhibitory conditioning to the tone, and therefore that the results provide evidence of interference with inhibitory conditioning to a preexposed stimulus, just as Experiment 1 provides evidence of interference with excitatory conditioning. One might, perhaps, argue that this assumption was unjustified, and that the discrimination between the light and the tone-light compound involved inhibitory conditioning not to the tone but to the compound as such. In Pavlov's (1927) terms, differential reinforcement in Stage 3 did not establish conditioned inhibition to the tone, but did establish differential inhibition to the tone-light compound. There is evidence that compounding or configural conditioning does occur under certain circumstances (Baker, 1968; Rescorla, 1972), but this evidence suggests that such configural learning proceeds at best slowly and laboriously, and of ten requires explicit differential reinforcement (in the present context, reinforcement of both light and tone alone and nonreinforcement of the tonelight compound). Perhaps the most cogent objection to any configural analysis of the present results, however, is that it does not explain the observed ordering of the groups. There is no apparent reason why preexposure to the tone should prevent subjects from learning that the tone-light compound was not reinforced.

One feature of the present results requires some comment. Although Group Tone/Water clearly responded at a higher rate on-tone-light trials than the remaining groups, some of these differences were already apparent on the first day of Stage 3. Figure 2 does not particularly suggest that the difference between Group Tone/Water and Groups Water and Control was increasing during the course of Stage 3, as one might expect it to if the cause of the difference were solely the retardation of inhibitory conditioning in Group Tone/Water.

Some of the differences between groups apparent on Day 1 in Figure 2 must surely be attributable to external inhibition (Pavlov, 1927). Pavlov reported that a novel stimulus, when presented in conjunction with an established $\mathrm{CS}+$, might transiently disrupt the responding normally maintained by that CS. For Groups Water and Control, the tone was a novel stimulus at the beginning of Stage 3, and it seems probable that this contributed to their low level of responding at this point. The large increase apparent in the control group's rate of responding on tone-light trials from Day 1 to Day 2 is entirely consistent with such an interpretation, as also is the fact that over Days 1-3 both Groups Tone and Tone/Water, for whom the tone was a familiar stimulus, responded at a higher rate on tone-light trials than did the two groups for whom the tone was novel. It is difficult to understand, however, why Groups Water and Control should have shown different patterns of responding over these days.

It should also be noted that the data shown in Figure 2 are plotted in blocks of five trials. Thus the first data point may already reflect differences due to different rates of inhibitory conditioning (just as differences on Day 1 in Figure 1 also may be presumed to reflect differences in the amount of excitatory conditioning that has occurred by the end of the day). Since the programming equipment did not record trial-by-trial scores, it is unfortunately impossible to test this assumption, but it seems to be the most reasonable interpretation of the difference between Groups Tone and Tone/Water on Day 1 of the present experiment.

\section{CONCLUSIONS}

The present experiments have confirmed that excitatory conditioning is retarded by prior nonreinforced presentations of the $\mathrm{CS}$ alone and, more severely, by uncorrelated presentations of the CS and UCS. They have also confirmed that inhibitory conditioning is retarded by prior nonreinforced presentations of the CS, and have shown that inhibitory conditioning is even more retarded by uncorrelated presentations of CS and UCS. They establish, therefore, the essential symmetry of latent inhibition (produced by nonreinforced presentations of the CS) and of what we have termed learned irrelevance (produced by uncorrelated presentations of CS and UCS).

The symmetry of these effects is of some import- 
ance, for it rules out any simple explanation in terms of competing responses. If a particular treatment interferes with excitatory conditioning to a given $\mathrm{CS}$, this may be because it has established some other response to the CS which interferes with the development of the appropriate CR during excitatory conditioning. Any such competing response, however, would presumably facilitate, rather than interfere with, the development of inhibitory conditioning to that CS. Neither latent inhibition nor learned irrelevance, therefore, can be entirely a consequence of the establishment of competing responses.

Other explanations of latent inhibition have been termed nonassociative by Halgren (1974), and categorized by both him and Rescorla (1971) as postulating changes either in the attention paid to, or the salience attached to, particular stimuli. If this sort of explanation is tentatively accepted, the question still remains as to how to explain the difference between latent inhibition and learned irrelevance: it is clear from our data that exposure to a zero correlation between CS and UCS has a greater effect on subsequent conditioning than does exposure to the CS alone. Mackintosh (1975) has suggested that while latent inhibition may be due to a general decline in attention to a preexposed stimulus, learned irrelevance may reflect, in addition, a specific decline in the associability of that stimulus with the uncorrelated reinforcer. An alternative, perhaps simpler, possibility is that the retardation of subsequent conditioning produced by uncorrelated presentations of CS and UCS is due to the sum of two independent effects, latent inhibition to the CS and "habituation" of the UCS. There is nothing in our results that would allow us to distinguish between these two possibilities.

\section{REFERENCES}

Baker, T. W. Properties of compound conditioned stimuli and their components. Psychological Bulletin, 1968, 70, 611-625.

Benedict, J. O., \& AYres, J. J. B. Factors effecting conditioning in the truly random control procedure in the rat. Journal of Comparative and Physiological Psychology, 1972, 78, 323-330."

GAmzU, E., \& Williams, D. R. Classical conditioning of a complex skeletal response. Science, 1971, 171, 923-925.

Halgren, C. R. Latent inhibition in rats: Associative or nonassociative? Journal of Comparative and Physiological Psychology, 1974, 86, 74-78.

KREMER, E. F. Truly random and traditional control procedures in CER conditioning in the rat. Journal of Comparative and Physiological Psychology, 1971, 76, 441.448.

Lubow, R. E., \& Moore, A. U. Latent inhibition: The effect of nonreinforced preexposure to the conditioned stimulus. Journal of Comparative and Physiological Psychology, 1959, 52, 415-419.

Mackintosh, N. J. Stimulus selection: Learning to ignore stimuli that predict no change in reinforcement. In $R$. A Hinde \& J. S. Hinde (Eds.), Constraints on learning. London: Academic Press, 1973. Pp. 75-96.

Mackintosh, N. J. A theory of attention: Variations in the associability of stimuli with reinforcement. Psychological Review, 1975, 82, 276-298.

Pavlov, 1. P. Conditioned reflexes. Oxford: Oxford University Press, 1927.

ReISs, S., \& W AGNER, A. R. CS habituation produces a "latent inhibition effect" but no active conditioned inhibition. Learning and Motivation, 1972, 3, 237-245.

Rescorla, R. A. Predictability and number of pairings in Pavlovian fear conditioning. Psychonomic Science, 1966, 4. 383-384.

Rescorla, R. A. Summation and retardation tests of latent inhibition. Journal of Comparative and Physiological Psychology, 1971, 75, 77-81.

Rescorla, R. A. "Configural" conditioning in discrete-trial bar pressing. Journal of Comparative and Physiological Psychology, 1972, 79, 307-317.

RODGER, R. S. Type II errors and their decision basis. British Journal of Mathematical and Statistical Psychology, 1967, 20, 187-204.

RODGER, R. S. The number of non-zero, post hoc contrasts from ANOVA and error-rate. British Journal of Mathematical and Statistical Psychology, 1975, 28, 71-78.

SCHEFfE, H. The analysis of variance. New York: Wiley, 1959.

Weisman, R. G., \& Litner, J. S. Positive conditioned reinforcement of Sidman avoidance behavior in rats. Journal of Comparative and Physiological Psychology, 1969, 68, 597-603.

WINER, B. J. Statistical principles in experimental design. New York: McGraw-Hill, 1971.

(Received for publication July 27, 1976; revision accepted April 28, 1977.) 